\title{
Effect of Mindfulness Based Cognitive Therapy on the Mental Health and Quality of Life in Patients with Breast Cancer
}

\author{
XIAOMIN CHU, YING LOU, ZIJUN WANG AND QIN XU1* \\ The Second Affiliated Hospital of Nanjing Medical University, 1college of Nursing, Nanjing Medical University, Nanjing, Jiangsu \\ 210011, China
}

\section{Chu et al.: Effect of MBCT on the Mental Health in Patients with Breast Cancer}

\begin{abstract}
To study the effect of mindfulness based cognitive therapy on the mental health and quality of life of breast cancer patients. A total of 84 breast cancer patients who underwent the surgical resection in the department of breast surgery in our hospital from August 2017 to August 2018 were selected. The 84 patients were randomly divided into the mindfulness based cognitive therapy intervention group $(n=42)$ and the control group $(n=42)$. The patients in the mindfulness based cognitive therapy group received an $8 \mathrm{w}$ mindfulness based cognitive therapy training, while the patients in the control group only received the routine nursing during this period. After the 8th $\mathrm{w}$, the patients in the control group and mindfulness based cognitive therapy group received the same mindfulness based cognitive therapy training program, and the changes in mental health and quality of life of the patients in the two groups were evaluated after 8 and $12 \mathrm{w}$ of intervention. Compared with the control group, the psychological perplexity [anxiety (Hospital Anxiety and Depression Scale-A) and depression (Hospital Anxiety and Depression Scale-D)], fear of cancer and mental health in the mindfulness based cognitive therapy group were significantly improved in the 8th $w$, and the difference between the two groups was still significant at the 12 th $w(p<0.05)$. After the intervention, the results showed that the fatigue degree in the mindfulness based cognitive therapy group were significantly reduced and the quality of life was significantly improved $(p<0.05)$. Mindfulness based cognitive therapy can improve the psychological, physiological and mental state of the patients with non-metastatic breast cancer, which is worth popularizing and applying in the clinic.
\end{abstract}

Key words: Mindfulness cognition, breast cancer, nursing, mental health, quality of life

Breast cancer was one of the most common cancers in women $^{[1]}$. Due to a variety of physical, psychosocial and mental problems that occurred during the illness and treatment, more than $50 \%$ of the breast cancer patients experienced the clinically significant psychological problems $^{[2,3]}$. Even for the patients with a good prognosis or patients who have completed the cancer treatment, the potential risk of cancer progression and recurrence were still cause the long-term problems for the patients and survivors, that was the fear of cancer recurrence $(\mathrm{FCR})^{[4,5]}$. In addition, the physical symptoms, such as fatigue and pain, can affect the patients' social function and quality of life (QOL) [6,7]. In fact, the FCR and fatigue were the two most common symptoms of the cancer survivors after completing the cancer treatment ${ }^{[4-6,8]}$. Recently, the mindfulness-based method has been widely used in cancer care ${ }^{[9]}$. The mindfulness-based intervention (MBI) guides patients to focus on the present and to develop a compassionate attitude towards life through meditation, yoga, group discussions, and daily meditation exercises, which promoted the better control of the emotion, cognition, and behavior of patients ${ }^{[9,10]}$. The mindfulness-based stress reduction (MBSR) and mindfulness-based cognitive therapy (MBCT) was the most commonly used MBI. Although there was no substantial difference between the two methods, MBCT combines cognitive therapy to provide a clearer psychological education on the relationship between the emotion, cognition, and function. A series of systematic retrospective studies have shown that the MBI can alleviate the psychological perplexity of the cancer patients effectively ${ }^{[11-13]}$. However, the effectiveness of MBI in the treatment of physical symptoms has been controversial. Although 
some studies have shown that the MBI has a beneficial effect on the fatigue and pain ${ }^{[14]}$, the results were not consistent $^{[14,15]}$. In addition, studies on the breast cancer patients have mainly focused on MBSR, and there were only a few randomized controlled trials of MBCT in this area. Of these MBCT trials, only one study focused on the breast cancer patients ${ }^{[16]}$. In this study, MBCT method was used to guide the condition and life of the postoperative breast cancer patients, and to explore the effect of MBCT on the mental health and QOL of the postoperative breast cancer patients.

A total of 84 breast cancer patients who underwent the surgical resection in the department of breast surgery in our hospital from August 2017 to August 2018 were selected. Inclusion criteria: The breast cancer stages of the patients were between 0 and stage III. The age of the patients was between 20-74 y old. The total Hospital Anxiety and Depression Scale (HADS) score of the patient was $\geq 5$. The Eastern Cooperative Oncology Group Performance State (ECOG-PS) score of the patients was 2-4. The clinical prognosis of the patient was $\geq 1 \mathrm{y}$. The patients have good communication skills. The patient signed a written informed consent form. Exclusion criteria: The patient has the experience of MBCT or MBSR, and the patients have any serious physical or mental symptoms.
The 84 patients were randomly divided into the MBCT intervention group $(\mathrm{n}=42)$ and the control group $(n=42)$. The basic clinical data of the two groups were shown in (Table 1). Through the statistical analysis, the two groups were comparable in the age, education level, body weight and medical history $(p>0.05)$. The intervention group received the MBCT training for $8 \mathrm{w}$ ( $2 \mathrm{~h}$ per w) (Table 2 ). Based on the previous scheme, the modified MBCT training in this study was better for the breast cancer patient ${ }^{[17]}$. A brief psychological education was performed in the first training to explain and practice the suffering of the cancer patients and the process of MBCT. MBCT includes the formal meditation exercises, psychological education based on the cognitive therapy, and discussions and interactions among participants. Participants were assigned some homework for each class, which takes 20 to $45 \mathrm{~min}$ to complete every d. At the same time, we provide participants with a Compact Disc Read-Only Memory (CD-ROM) of meditation guides. The therapists were composed of the clinical psychologists, psychiatrists, and nurses with 5 to $7 \mathrm{y}$ of mindfulness experience, and complete MBCT training. The therapist follows the schedule of the intervention agreement at training to ensure the integrity of the treatment. A research assistant recorded the training process and checked the treatment compliance. For patients assigned to the

TABLE 1: THE BASIC CLINICAL DATA OF THE TWO GROUP

\begin{tabular}{|c|c|c|c|c|c|c|c|}
\hline \multicolumn{8}{|c|}{ Education level } \\
\hline Group & $\mathrm{n}$ & Age (y old) & $\begin{array}{c}\text { Below than senior } \\
\text { high school }\end{array}$ & $\begin{array}{l}\text { Over than senior } \\
\text { high school }\end{array}$ & $\begin{array}{l}\text { Weight } \\
\text { (Kg) }\end{array}$ & $\begin{array}{c}\text { Medical } \\
\text { history (mon) }\end{array}$ & $\begin{array}{l}\text { Length of } \\
\text { stay (mon) }\end{array}$ \\
\hline $\begin{array}{l}\text { Intervention } \\
\text { group }\end{array}$ & 42 & $54.6 \pm 5.7$ & 9 & 33 & $48.7 \pm 6.9$ & $3.1 \pm 1.1$ & $10.5 \pm 3.8$ \\
\hline $\begin{array}{l}\text { Control } \\
\text { group }\end{array}$ & 42 & $54.9 \pm 6.3$ & 11 & 31 & $49.3 \pm 7.4$ & $3.2 \pm 0.8$ & $10.2 \pm 4.1$ \\
\hline $\mathrm{t}$ & & 0.251 & \multicolumn{2}{|c|}{0.487} & 0.151 & 0.185 & 0.566 \\
\hline $\mathrm{p}$ & & 0.821 & \multicolumn{2}{|c|}{0.431} & 0.902 & 0.886 & 0.357 \\
\hline
\end{tabular}

TABLE 2: COMPARISON OF THE PSYCHOLOGICAL DISTURBANCE BETWEEN TWO GROUPS

\begin{tabular}{|c|c|c|c|c|c|}
\hline Items & MBCT group & Control group & Mean difference & $\mathrm{t}$ value & $\frac{\mathrm{P}}{\text { value }}$ \\
\hline \multicolumn{6}{|l|}{ HADS-overall } \\
\hline Before treatment & $16.09 \pm 7.21$ & $14.81 \pm 6.99$ & 1.28 & 0.531 & 0.876 \\
\hline 8th week of treatment & $6.23 \pm 4.45$ & $14.00 \pm 8.00$ & -7.77 & 6.743 & 0.008 \\
\hline $\begin{array}{c}\text { 12th week of treatment } \\
\text { HADS-Anxiety }\end{array}$ & $6.88 \pm 5.76$ & $13.33 \pm 6.97$ & -6.45 & 5.787 & 0.013 \\
\hline Before treatment & $8.34 \pm 3.52$ & $7.98 \pm 3.36$ & 0.36 & 0.103 & 0.926 \\
\hline 8th week of treatment & $3.51 \pm 2.62$ & $6.97 \pm 3.98$ & 3.48 & 3.521 & 0.027 \\
\hline $\begin{array}{c}\text { 12th week of treatment } \\
\text { HADS-Depression }\end{array}$ & \multicolumn{4}{|c|}{ HADS-Depression } & 0.036 \\
\hline Before treatment & $7.74 \pm 4.38$ & $7.59 \pm 4.21$ & 0.15 & 0.092 & 0.955 \\
\hline 8th week of treatment & $2.38 \pm 2.82$ & $7.33 \pm 4.53$ & 5.05 & 5.217 & 0.016 \\
\hline 12th week of treatment & $2.92 \pm 2.98$ & $6.79 \pm 4.17$ & 4.13 & 4.873 & 0.02 \\
\hline
\end{tabular}


intervention group, there was no restriction on any joint intervention during the study period.

The patients in the control group only received the general psychological counseling and routine nursing during the MBCT training in the intervention group. When the intervention group finished the MBCT training course, the two groups were treated with all the projects together during the 8th-12th w. Evaluation of the patient's psychological disturbance (anxiety and depression). The psychological disturbance of the patients was measured by the HADS. HADS was a 14-item self-management questionnaire; each item includes seven levels of anxiety and depression. The score was from 0 (no impact) to 21 (most serious), the higher score means the more anxious.

FCR. A concern about recurrence scale (CARS) was used to assess the FCR of the patients. CARS has been confirmed to measure the FCR in the breast cancer patients. In this study, to reduce the management burden of the participants, only the subscale of "overall FCR" (four items) was used. The higher scores indicate a higher level of FCR. Degree of fatigue in the patients. Brief fatigue inventory (BFI) was used to assess the degree of fatigue of the participants. BFI was an effective measurement method, which consists of 10 items. The higher scores indicate the more serious of the fatigue. Mental health of the patient. The functional assessment of chronic illness therapy-spiritual wellbeing (FACITSp) was used to evaluate the mental health of the patients. The FACITSp contained 12 selfmanagement evaluations, including two subscales, life significance and living faith. QOL of the patients. The functional assessment of cancer therapy-general (FACT-G) was used to evaluate the QOL of the patients. The FACT-G questionnaire includes four areas-physical, social, emotional, and functional health, and consists of 27 questions, the higher scores indicating the better QOL. Evaluation of the patients' mindfulness ability. The five facet mindfulness questionnaire (FFMQ) was used to evaluate the mindfulness ability of the patients, which was widely used to assess whether the participants have accepted mindfulness during the intervention. A total of 39 mindfulness skills in the five areas were tested in the FFMQ, including the observation, description, action and consciousness, self-cognition and psychological reaction.

SPSS 18.0 was used for the data analysis, the data were normally distributed, and the output data was expressed as average \pm standard deviation $(\overline{\mathrm{x}} \pm \mathrm{s})$. The independent t-test was used to analyze the differences among groups, and $p<0.05$ means the difference was statistically significant. Compared with the control group, the psychological disturbance (HADS-A, HADS-D) of the MBCT group were significantly improved in the 8th w, and the average difference of the total score of HADS was -7.82 , and the difference between the two groups was statistically significant $(\mathrm{p}<0.05)$. In the $12 \mathrm{w}$, the difference between the two groups was still significant (Table 2). Compared with the control group, the FCR and mental health in the MBCT group were significantly improved after treatment, especially the mental health was improved significantly (Table 3 ).

Compared with the control group, the fatigue degree of patients in MBCT group was significantly decreased, the difference was statistically significant $(\mathrm{p}<0.05)$. The level of QOL in the MBCT group was significantly higher than that in the control group $(\mathrm{p}<0.05)$. All these data indicate that MBCT can improve the QOL of patients and reduce the degree of fatigue of patients significantly (Table 4). The results showed that the mindfulness skills in the MBCT group were significantly better than that in the control group, and the difference was still significant after $12 \mathrm{w}$ of treatment, which indicated that our training was effective for the patients (Table 5). At present, the radiotherapy combined with chemotherapy was used for the postoperative breast cancer patients, which has a series of side effects, such as nausea, vomiting, hair loss and pain. At the same time, the patients will experience the fear, anxiety and mood swings during the treatment, which has a great

TABLE 3: FCR AND MENTAL HEALTH STATUS OF PATIENTS IN TWO GROUPS

\begin{tabular}{|c|c|c|c|c|c|}
\hline Items & MBCT group & Control group & Mean difference & $\mathrm{t}$ value & $\mathrm{p}$ value \\
\hline \multicolumn{6}{|l|}{ FCR } \\
\hline Before treatment & $13.47 \pm 5.20$ & $13.57 \pm 5.43$ & 0.1 & 0.078 & 0.941 \\
\hline 8th week of treatment & $8.77 \pm 4.88$ & $12.69 \pm 4.78$ & -3.92 & 3.881 & 0.022 \\
\hline $\begin{array}{l}\text { 12th week of treatment } \\
\text { FACITSp }\end{array}$ & \multicolumn{4}{|c|}{ FACITSp } & 0.024 \\
\hline Before treatment & $21.58 \pm 7.98$ & $21.28 \pm 7.43$ & 0.3 & 0.125 & 0.895 \\
\hline 8th week of treatment & $32.70 \pm 9.64$ & $24.61 \pm 8.54$ & 8.09 & 3.881 & 0.022 \\
\hline 12 th week of treatment & $32.51 \pm 10.93$ & $24.83 \pm 8.74$ & 7.68 & 3.432 & 0.024 \\
\hline
\end{tabular}


TABLE 4: FATIGUE DEGREE AND QOL CHANGES IN TWO GROUPS

\begin{tabular}{|c|c|c|c|c|c|}
\hline Items & MBCT group & Control group & Mean difference & $\mathrm{t}$ value & $\mathrm{p}$ value \\
\hline \multicolumn{6}{|l|}{$\mathrm{BFI}$} \\
\hline Before treatment & $3.54 \pm 2.28$ & $3.22 \pm 2.42$ & 0.32 & 0.134 & 0.902 \\
\hline 8th week of treatment & $1.8 \pm 0.80$ & $3.37 \pm 2.81$ & -1.57 & 2.065 & 0.040 \\
\hline 12th week of treatment & $1.81 \pm 0.84$ & $3.04 \pm 2.37$ & -1.53 & 2.000 & 0.042 \\
\hline \multicolumn{6}{|l|}{ FACT-G } \\
\hline Before treatment & $65.20 \pm 16.77$ & $68.91 \pm 16.63$ & 0.3 & 0.125 & 0.895 \\
\hline 8th week of treatment & $84.94 \pm 14.59$ & $71.59 \pm 18.73$ & 13.35 & 6.540 & 0.001 \\
\hline 12th week of treatment & $85.41 \pm 16.08$ & $71.90 \pm 18.50$ & 13.51 & 6.612 & $<0.001$ \\
\hline
\end{tabular}

TABLE 5: EVALUATION OF THE MINDFULNESS ABILITY BETWEEN THE 2 GROUPS

\begin{tabular}{|c|c|c|c|c|c|}
\hline Items & MBCT group & Control group & Mean difference & t value & p value \\
\hline \multicolumn{6}{|l|}{ FFMQ } \\
\hline Before treatment & $117.32 \pm 18.40$ & $117.89 \pm 13.03$ & -0.57 & 0.368 & 0.868 \\
\hline 8th week of treatment & $133.67 \pm 17.87$ & $120.47 \pm 14.37$ & 13.20 & 6.371 & 0.003 \\
\hline 12 th week of treatment & $137.03 \pm 18.85$ & $119.19 \pm 13.44$ & 17.84 & 8.961 & $<0.001$ \\
\hline
\end{tabular}

impact on the patient's recovery and QOL. Conventional nursing methods only guide and help patients with the adverse reactions and medication, but ignore the changes of patients' psychological state, which may be one of the main reasons for the poor prognosis of patients. Mindfulness emphasizes the individual, paying attention to the present and accepting the present state. This is helpful to dredge the emotions ${ }^{[17]}$ of patients, reduce the attention to the disease, and deal with stress and pain. After mindfulness training, the emotion regulation ability and cognition of the patient will be greatly improved and changed ${ }^{[18,19]}$. Through the correct understanding of themselves, to help the patients rebuild their cognitive structure and eliminate bad emotions. Our research shows that the MBCT intervention significantly reduces the psychological burdens (including anxiety and depression) in patients with non-metastatic breast cancer. In addition, the MBCT intervention care was effective in improving the lives of the breast cancer patients, improving their mental health and QOL, and reducing the FCR and fatigue.

After the MBCT intervention, the total score of HADS decreased from 13.47 to 7.98 . The cancer patients with total HADS score $\geq 13$ were considered to need psychotumor support ${ }^{[20]}$. In this study, MBCT helps to reduce the psychological disturbance of the patients, and has a significant effect on the improvement of anxiety and depression, which is consistent with the previous studies $^{[21]}$. The results of this study showed that the MBCT can reduce the FCR of patients. FCR was one of the most common problems for the cancer survivors. As we all know, FCR will not disappear even for a long time after cancer remission, so it is of great clinical significance to reduce or alleviate the FCR of patients ${ }^{[4]}$. So far, a large number of studies have developed some psychological methods to solve the $\mathrm{FCR}^{[18-20]}$. MBCT in this study may have more advantages, because it is not only effective for FCR, but also can reduce other psychological burdens. In addition, we found that the MBCT relieved the fatigue of the patients. Fatigue was one of the two most common symptoms of the cancer survivors, which seriously damaging the QOL of the cancer patients. At present, there was no effective drug to treat the fatigue of the cancer patients, although the physical exercise and sleep management have been confirmed to be effective ${ }^{[11]}$, the effects were not satisfactory ${ }^{[8]}$. MBCT intervention greatly improved the QOL and mental health of the patients. It is worth noting that the MBCT not only reduces the negative psychology of the cancer patients, but also improves their positive attitude towards the daily life. Mental health helps to relieve the clinically important problems such as pain, fatigue, depression and the death desire ${ }^{[21]}$. Although the cancer patients are in danger of life, mindfulness cognition gives patients a sense of integrity and internal unity, which may trigger the awakening of the selfinsight into the meaning of life in the cancer patients. In a word, the MBCT therapy established specifically for the breast cancer patients in this study significantly improved the symptoms of the patients, and improved the QOL of the patients after operation.

\section{Author's contributions:}

Qin $\mathrm{Xu}$ experiments; conceived and designed the Ying Lou and Zijun Wang performed the experiments; Xiaomin Chu analyzed the data and wrote the paper. 


\section{Acknowledgement:}

This work was supported by The Second Affiliated Hospital of Nanjing Medical University.

\section{Conflict of Interests:}

The authors declared no conflict of interest.

\section{REFERENCES}

1. Mitchell AJ, Chan M, Bhatti H, Halton M, Grassi L, Johansen $\mathrm{C}$ et al. Prevalence of depression, anxiety, and adjustment disorder in oncological, haematological, and palliative-care settings: a meta-analysis of 94 interview-based studies. Lancet Oncol 2011;12:160-74.

2. Hegel MT, Moore CP, Collins ED, Kearing S, Gillock KL, Riggs RL et al. Distress, psychiatric syndromes, and impairment of function in women with newly diagnosed breast cancer. Cancer 2006;107:2924-31.

3. Matchim Y, Armer JM, Stewart BR. Effects of mindfulnessbased stress reduction (MBSR) on health among breast cancer survivors. West J Nurs Res 2011;33:996-1016.

4. Deirdre Kiely RN AN, Schwartz S. Mindfulness as an Intervention for Breast Cancer Survivors. Clin J Oncol Nurs 2016; 20:357.

5. Simard S, Thewes B, Humphris G, Dixon M, Hayden C, Mireskandari S, et al. Fear of cancer recurrence in adult cancer survivors: a systematic review of quantitative studies. J Cancer Surviv 2013;7:300-22.

6. Hamer J, McDonald R, Zhang L, Verma S, Leahey A, Ecclestone C, et al. Quality of Life (QOL) and Symptom Burden (SB) in patients with breast cancer. Support Care Cancer 2017;25:409-19.

7. Piet J, Würtzen H, Zachariae R. The effect of mindfulnessbased therapy on symptoms of anxiety and depression in adult cancer patients and survivors: a systematic review and metaanalysis. J Consult Clin Psychol 2012;80:1007-20.

8. Schell KL, Monsef I, Wockel A, Skoetz N. Mindfulness-based stress reduction for women diagnosed with breast cancer. Cochrane Database Syst Rev 2019;3:CD011518.

9. Lesiuk T. The Effect of Mindfulness-Based Music Therapy on Attention and Mood in Women Receiving Adjuvant Chemotherapy for Breast Cancer: A Pilot Study. Oncol Nurs Forum 2015;42.

10. Maass SW, Roorda C, Berendsen AJ, Verhaak PF, de Bock $\mathrm{GH}$. The prevalence of long-term symptoms of depression and anxiety after breast cancer treatment: a systematic review. Maturitas 2015;82:100-8.
11. Mohammadi PK, Zargar NA, Shahidi MA. The Efficacy of Mindfulness Therapy on Mindfulness Attention Awareness and Perception of Disease in Women with Breast Cancer. Indian J Public Health Res Dev 2018;9:157-61.

12. Traeger L, Greer JA, Fernandez-Robles C, Temel JS, Pirl WF. Evidence-based treatment of anxiety in patients with cancer. J Clin Oncol 2012;30:1197-205.

13. Carlson LE. Mindfulness-based interventions for coping with cancer. Ann N Y Acad Sci 2016;1373:5-12.

14. Lesiuk T. The Effect of Mindfulness-Based Music Therapy on Attention and Mood in Women Receiving Adjuvant Chemotherapy for Breast Cancer: A Pilot Study. Oncol Nurs Forum 2015,42:276.

15. Huang HP, He M, Wang HY, Zhou M. A meta-analysis of the benefits of mindfulness-based stress reduction (MBSR) on psychological function among breast cancer (BC) survivors. Breast Cancer 2016;23:568-76.

16. Hirai K, Motooka H, Ito N, Wada N, Yoshizaki A, Shiozaki $\mathrm{M}$, et al. Problem-solving therapy for psychological distress in Japanese early-stage breast cancer patients. Jpn J Clin Oncol 2012;42:1168-74.

17. Gucht KVD, Melis M, Ahmadoun S, Gebruers A, Smeets A, Vandenbulcke $\mathrm{M}$, et al. A mindfulness-based intervention for breast cancer patients with cognitive impairment after chemotherapy: study protocol of a three-group randomized controlled trial. Trials 2020;21:1.

18. Ledesma D, Kumano H. Mindfulness-based stress reduction and cancer: a meta-analysis. Psychooncology 2009;18:571-9.

19. Zainal NZ, Booth S, Huppert FA. The efficacy of mindfulnessbased stress reduction on mental health of breast cancer patients: A meta-analysis. Psychooncology 2013;22:1457-65.

20. Stafford L, Foley E, Judd F, Gibson P, Kiropoulos L, Couper J. Mindfulness-based cognitive group therapy for women with breast and gynecologic cancer: a pilot study to determine effectiveness and feasibility. Support Care Cancer 2013;21:3009-19.

21. Wakefield CE, Butow PN, Aaronson NA, Hack TF, HulbertWilliams NJ, Jacobsen PB. Patient-reported depression measures in cancer: a meta-review. Lancet Psychiatry 2015;2:635-47.

This is an open access article distributed under the terms of the Creative Commons Attribution-NonCommercial-ShareAlike 3.0 License, which allows others to remix, tweak, and build upon the work non-commercially, as long as the author is credited and the new creations are licensed under the identical terms

This article was originally published in a special issue, "Biomedical Research in Clinical and Preclinical Pharmaceutics" Indian J Pharm Sci 2020:82(3)Spl issue7;48-52 